\title{
Dermatologists happiness and satisfaction
}

\author{
Leonel Fierro-Arias ${ }^{1}$, Pilar Simón-Díaz¹, Rosa María Ponce-Olivera ${ }^{1}$ and Roberto Arenas-Guzmán²
}

${ }^{1}$ Department of Dermatology, Hospital General de México Dr. Eduardo Liceaga; ${ }^{2}$ Department of Mycology, Hospital General Dr. Manuel Gea González, Ciudad de México, Mexico

\begin{abstract}
Objective: To assess the level of happiness and satisfaction in the life and medical practice of dermatologists in Mexico. Method: A descriptive study (online survey) was conducted focused on practicing dermatologists in our country. Questions included demographic characteristics, the Pemberton happiness index (with local validation) and questions that assessed the degree of personal satisfaction. Descriptive statistics were used to obtain the central tendency and dispersion. Measures of central tendency and dispersion were performed; to compare categorical variables, contingency tables for chi-square test were used and when comparing quantitative variables with normal distribution, Student's $t$ t-test was used. Results: 219 surveys were included, $72.6 \%$ female and $27.4 \%$ male, with an average age of 45.6 and an average of 16 years of medical practice. Most of them (64.8\%) graduate from Mexico City; $93 \%$ were very satisfied with the specialty and $98.6 \%$ of them would choose the same once again, the most important reason is to encompass medical and surgical areas. The level of happiness by using the Pemberton scale was "high" (mode: 9.11; standard deviation: 1.73). Conclusions: This first study in Latin America on this subject in dermatologists showed high levels of satisfaction and happiness in both professional and personal areas.
\end{abstract}

KEY WORDS: Dermatology. Satisfaction. Happiness. Doctors.

\section{Introduction}

In recent years, and in different regions of the world, issues related to job satisfaction among healthcare professionals have gained attention. This concept is directly related to physicians' well-being and to the quality of the services that, as a consequence, they provide to their patients. Scientific studies on satisfaction or well-being are relatively recent; however, the importance individuals have given to feeling well or to harbor perceptions of happiness has its origin thousands of years back, and has shaped some of the most important traditions of thought of mankind'.

According to the World Health Organization, mental health is "a state of well-being in which every individual realizes his or her own potential, can cope with the normal stresses of life, can work productively and fruitfully, and is able to make a contribution to his or her community"2.

Well-being has two components: the hedonistic component, which consists of momentary pleasure or well-being, and the eudaimonic component, which focuses on self-fulfillment, psychologic growth, goals and necessities on the mid and long term ${ }^{3}$. A proposal of a eudaimonic psychological well-being multidimensional model integrates the following aspects: self-acceptance (the sensation of feeling well with oneself), positive relations with others, mastery of the environment where the individual carries out his/her activities, autonomy, having a purpose in life and personal growth $^{4}$. It is precisely due to this central role in human functioning that well-being evaluation is a highly important task and at the same time an interesting scientific challenge ${ }^{5}$.

\author{
Correspondence: \\ Leonel Fierro-Arias \\ Perpetua 40-3 piso \\ Col. San José Insurgentes, Benito \\ Juárez C.P. 03900, Ciudad de México, \\ México \\ E-mail: leofierro@yahoo.com
}

Date of reception: 16-07-2016

Date of acceptance: 18-08-2016

DOI://dx.doi.org/10.24875/GMM.M18000107
Gac Med Mex. 2018;154:16-24

Contents available at PubMed www.gacetamedicademexico.com 
Satisfaction at work depends both on environmental conditions and on characteristics of the surroundings, as well as on individual mental processes. The components of the workplace are diverse and some of them are not modifiable, but are with no doubt relevant, since they have an impact on the individual's perception, without forgetting that the elements of happiness or unhappiness also originate in people.

In this conception, there are two important aspects: the first one are the processes that can materialize on the short term (the way to cope and think in specific situations), when happiness is partially determined by comparative judgements, and the second one is established by an evaluation related to self-efficacy, novelty and personal relevance. Thus, one of job satisfaction's relevant characteristics is that the individual has to perceive self-fulfillment (the degree at which autonomy, new learning, etc. are valued $)^{6}$.

Other elements are established on the long term (arrangement or demographic aspects), and include personality traits and gender. This way, environmental and individual variables interact in a particular form in each person. On the other hand, cognitive, physical or character features influence on career and job choices, or on the inclination for particular activities in a job, which in turn has an impact on happiness ${ }^{6}$.

Surveys in different countries show that dermatologists have higher job satisfaction and less professional burnout than other physicians. To the best of our knowledge, and after a search for information, there are no evaluations on the degrees of satisfaction among those who practice this specialty in our country or in the rest of Latin America.

The purposes of this study were to assess the satisfaction and well-being of dermatologists in Mexico, to know whether this branch of medicine has fulfilled their professional expectations, to compare the degree of satisfaction and happiness of the study population with regard to investigations reported in other countries, and to correlate the degree of satisfaction with the institution where they had their dermatology training, as well as with some demographic characteristics.

\section{Methods}

A descriptive study was carried out using an online survey containing elements to obtain demographic data, the Pemberton Happiness Index (PHI) and some questions assessing the degree of satisfaction with the profession and the postgraduate training institution.
After informed consent with personal data confidentiality reservation was granted, the survey was applied to dermatologists practicing in our country who were graduates from any Mexican school, who had been trained as specialists and who were willing to participate in the study, regardless of age, gender, years of practice and workplace (institutional, private or both). For the sample size calculation, the equation for infinite populations without replacement was used, based on a proportion. In this case, the result was 0.7 , with a $95 \%$ confidence level and a margin of error of $6 \%$; the sample size yielded an $n=224$.

The database was obtained with information provided by the main national groups of the specialty. Via e-mail, all study subjects were sent an invitation letter, the survey with the described elements and the $\mathrm{PHI}$, using the Google Formats ${ }^{\odot}$ electronic tool. Subsequently, the level of satisfaction with the profession and with the school where they graduated was assessed by means of standardized methods.

A descriptive analysis was carried out for the following variables: age (years), professional practice (years), satisfaction with professional life, energy to fulfill everyday tasks, feeling that professional life is useful and valuable, and feeling satisfied with personal way of being. The mean, the standard deviation, upper and lower values and percentiles 25, 50 and 75 were obtained.

For the gender, training institution, satisfaction with specialty and with training institution, most relevant reason for satisfaction and "would study dermatology again" variables, frequencies were obtained and expressed as percentages, as well as in bar and pie charts for qualitative variables, and histograms for quantitative variables.

The PHI value for each individual was obtained by means of three steps: 1) the average of 10 variables that comprise the "remembered well-being" (eudaimonic scale), 2) average of 10 variables that comprise the "experienced well-being" (hedonic scale), and 3) the sum of these averages. The interpretation of the resulting values is as follows: from 0 to 3.70 , very low; from 3.71 to 5.90 , low; from 5.91 to 7.90 , intermediate; from 7.91 to 9.2 , high; and from 9.2 to 10 , very high.

For the processing of information, a database was generated in Microsoft Excel ${ }^{\circledR}$, and statistical analysis was carried out with the Statistical Package for the Social Sciences ${ }^{\circledR}$ (SPSS) version 22 software.

The PHI is obtained with a comprehensive scale, validated in 7 different languages, cultures and countries, 
including ours ${ }^{8}$. It contains 10 elements related to remembered well-being different domains (general, eudaimonic, hedonic), in addition to 11 experienced well-being elements, which can be transformed into a single well-being index.

The first dimension of the scale to be analyzed was "dimensionality", which was carried out by means of factor analysis and Pearson's simple linear correlations matrix. The number of implemented factors was equal to the number of initial self-values that were higher than 1, and Kaiser's Varimax rotation was used ${ }^{9}$.

"Reliability or trustworthiness", second dimension of the scale, was assesses with Cronbach's alpha ${ }^{10}$. This statistic is accompanied by the determination of the structure of the studied variables' association by means of Pearson's simple linear correlation coefficient, and is presented as an array of values known as "correlation coefficient matrix". The correlation analysis was complemented by a cluster analysis, which consists in forming homogeneous groups of variables; for this, the value of the simple linear correlation and the hierarchical method of the closest distance (obtained in previous paragraph) were used as a measure of association. A tree diagram was used for graphic configuration ${ }^{9}$.

The third analyzed dimension was "consistency of the scale", and to obtain it, a new dimensionality analysis was carried out with a sample of $50 \%$ of the original selection, in a random manner and by factor analysis (Mardia, Kent, Bibby, etc.) ${ }^{9}$.

\section{Results}

A total of 219 surveys were included. The results of the demographic variables are shown in table 1.

Surveys were received from doctors graduated from 16 different institutions in Mexico; the 3 most common correspond to institutions from Mexico City (Fig. 1).

In the dimension of satisfaction with the specialty, of all surveyed subjects, 204 (93.2\%) answered being "very satisfied", whereas $12(5.5 \%)$ referred being "moderately satisfied", and only $3(1.4 \%)$ considered feeling "little satisfied". In order of frequency, the most relevant reasons were that the dermatology specialty encompasses medical and surgical fields, with 101 answers (46.1\%); academic and research sphere, with 29 (13.2\%); being able to help others, together with the opportunity to see different types of patients, with $32(14.6 \%)$; and having flexible schedules and time to do other things, with 22 (10\%).

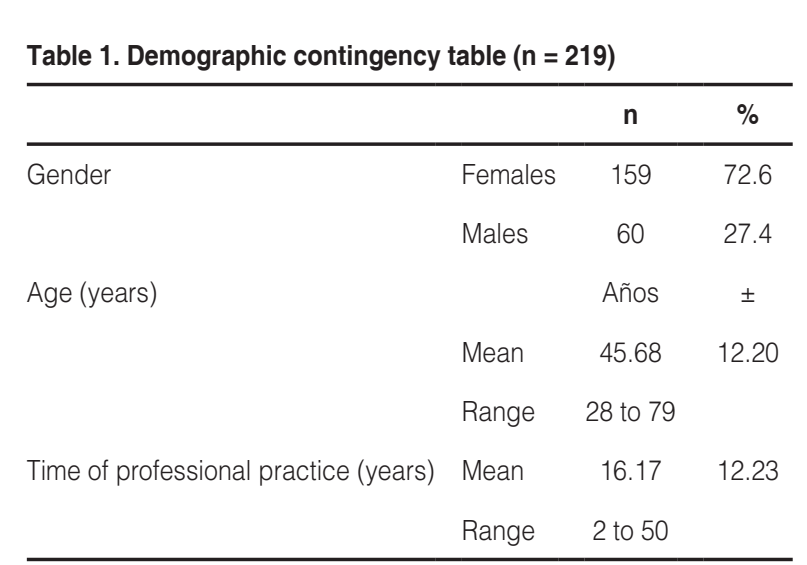

As for the training institution, 165 of surveyed subjects $(75.3 \%)$ answered being very satisfied; 47 (21.5\%) moderately satisfied; 6 (2.7\%) little satisfied, and one surveyed subject did not answer.

Among the surveyed population, 216 individuals $(98.6 \%)$ answered they would study dermatology as a specialty again.

Globally, when the PHI was used in this study, a mean score of $9.08( \pm 1.59)$ was obtained; when divided into its two dimensions, a mean score of $9.1( \pm 1.73)$ was generated for "remembered well-being" and a mean score of $8.78( \pm 1.26)$ for "experienced well-being". According to the results' interpretation, a "high" average satisfaction and happiness index was obtained, with a mean of 9.08 .

Reliability of the scale was determined with Cronbach's alpha, and it yielded a value of 0.955 , which is interpreted as being "high", since this statistic presents values comprised within a 0 to 1 interval.

Variables showed positive association values ranging from intermediate to high in magnitude, whereas the "there are moments when I feel bad" item shows no correlations or correlations with a very small value with regard to the other studied variables.

The cluster analysis is shown in the respective tree diagram and confirms the degree of association of the Pemberton scale items and the "there are moments when I feel bad" dissimilarity (Fig. 2).

Dimensionality of the scale was studied by means of an analysis of factors; the two first ones showed a variance $>1$ and, together, they accounted for $91.93 \%$ of total variance, which is a high percentage for this type of analysis. Each factor stands out for variables that show a high coefficient. The coefficients that characterize the factors of the scale variables showed a consistent pattern in the reliability analysis. The results to assess the consistency of the sample by means of an analysis of factors in a randomly selected sub-sample of $50 \%$, reflect similar results to those in the entire sample $(n=219)$. 


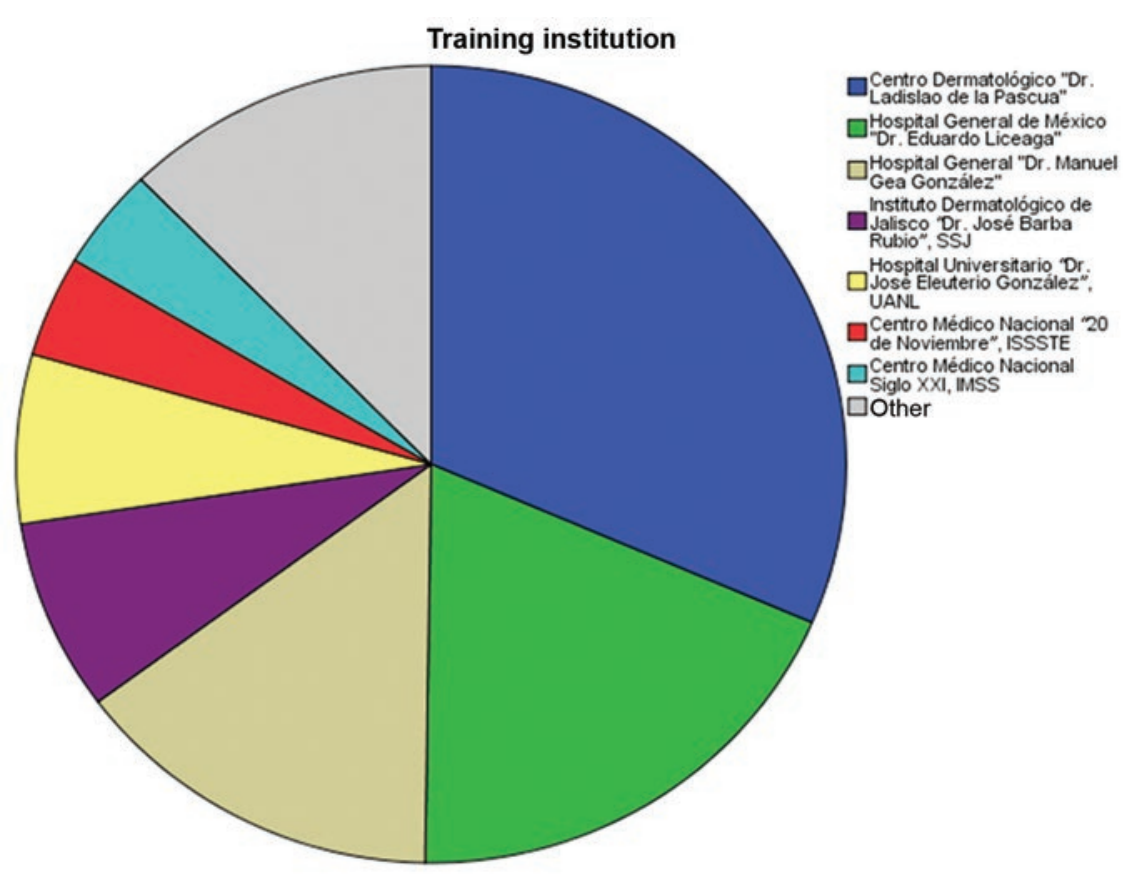

Figure 1. Participating dermatologists' distribution by training institutions.

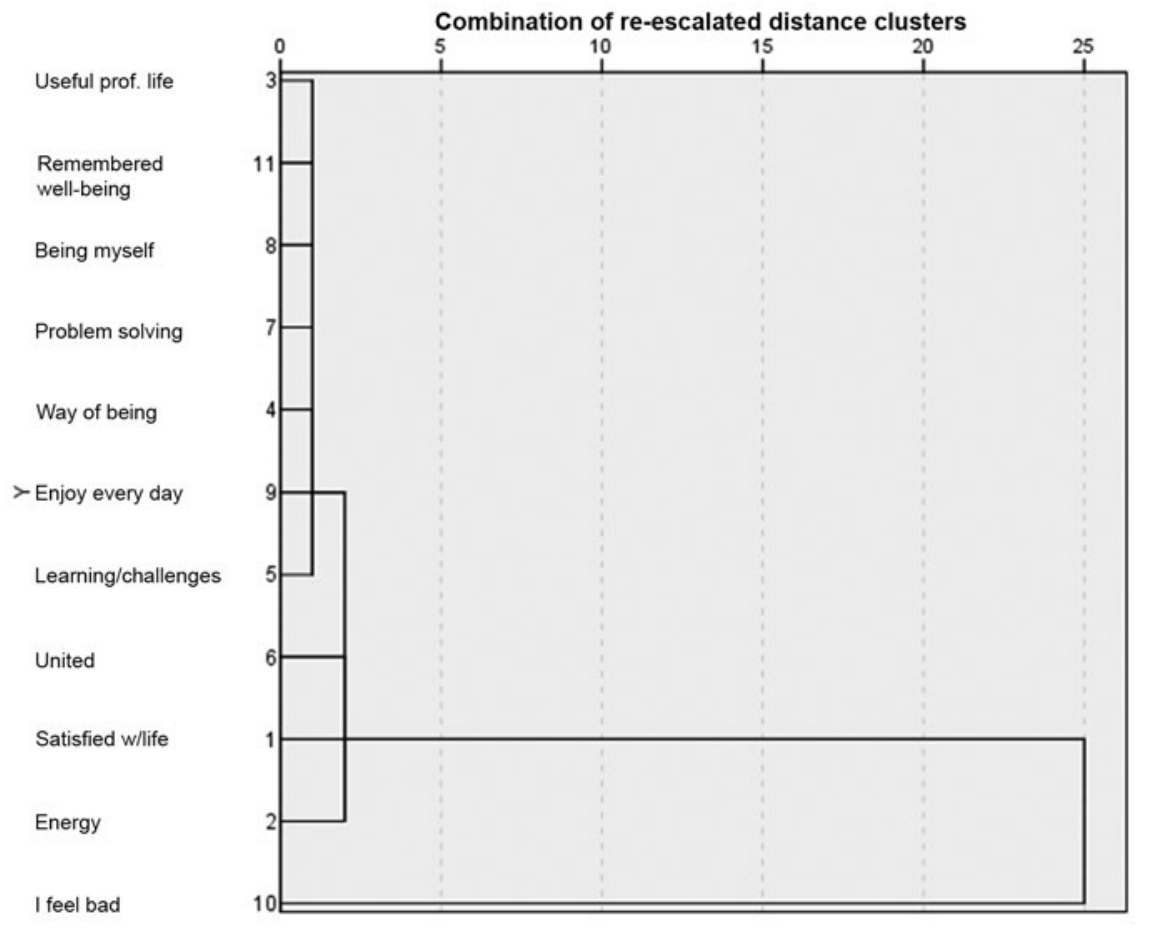

Figure 2. Dendogram of the variables comprising the Pemberton Happiness Index.

\section{Discussion}

Happiness is defined as a state of pleasant physical and spiritual satisfaction, a state of mind of plenitude and joy ${ }^{11,12}$. This concept is closely related to our perceptions in a given moment, by self-assessment, but also to the comparison with others. Hedonic experiences have been used as determinants of happiness and, currently, they can have relevance in other fields of research beyond the area of health, e.g. economic and even evolutionary, where an individual's perception of success is understood as not only depending on his/her economic conditions, but also on a current comparison between these conditions and the previous ones, the 
situation of the individual's peers and the surroundings where he/she functions ${ }^{13}$.

Several interpersonal coexistence and work organization structural factors have been associated with professional stress and chronic burnout. The perception of job satisfaction has a protecting impact against occupational stress negative consequences. For medicine professionals, job satisfaction has been described to largely depend on good relationships with workmates (either superiors or subordinates), on relationships with patients, on available leisure time, on intrinsic values, on the type of community where activities are carried out, on satisfaction with the specialty, on having enough resources and on autonomy at work $^{14,15}$. Several studies have reported that satisfaction at work has a protecting effect against professional burnout syndrome $e^{16,17}$.

The practice of medicine has undergone relevant changes in the last decades and, although various efforts have been made to discover their nature and impact on users' satisfaction, they have not allowed understanding how doctors experience or face changes in the dynamics of their profession ${ }^{18}$.

The influence of occupational stress has broadened and, specifically in the case of health professionals, it is patent and recurrent. Different studies have revealed that, since undergraduate training, students have higher levels of stress in medicine than in other majors and develop different coping strategies with this regard ${ }^{19}$.

Three socio-occupational elements that are linked to the professional field of the area of health have been pointed out as being relevant to the impact of medical practice and to trigger occupational stress:

1) Overload in the number of patients requiring attention, which results in emotional and mental overload.

2) Increase in macroeconomic demands, which implies, as a consequence, an increase in workers' adaptation requirements.

3) Deterioration of working conditions with increased working hours, limited promotion, forced or descending changes in work positions, career or assignment changes, eventual unemployment and early retirement (non-justified or disease-related) ${ }^{20}$.

Job satisfaction predictors have been identified, which can be classified as intrinsic and extrinsic. The former include the intention of remaining on the job position, the possibility of coping with problem solving, satisfaction with life in general and some well-being measurements, such as the correlation between expectations and achievements, adequate mental management and perceived support from immediate family. Extrinsic predictors include perceived support from the organization and higher possibilities of upgrade and promotion at work ${ }^{21}$.

There are different references describing that satisfaction among those who practice medicine is declining $^{22-25}$. Dissatisfaction appears to be explained by an increase in public and patient expectations or demands, higher pressure of working hours, cost restrictions and regulatory controls, which threaten medical practice autonomy and freedom ${ }^{25}$.

Professional satisfaction is variable in different medical specialties. This is highly interesting and important, since a strong relationship has been found between the well-being obtained by the patient when being attended to and the results he/she expected from the beginning. Doctors' dissatisfaction at workplaces originates their need to associate in unions, to protest, and for them to experience personal health problems and even to completely abandon their profession. In sum, and in order for this to be taken into account, doctors' low levels of satisfaction can increase stress and errors in their professional practice, which puts patients' safety at risk.

In recent years, in digital media, reports of studies based on surveys have been diffused, which not always explain the research methodologies, where dermatologists occupy the highest positions in terms of happiness; for example, the medical diffusion company Doctoralia ${ }^{\circledR}$ revealed a few months ago in digital press media that, in Spain, dermatologists are located at second place after psychologists (in Mexico, psychology is not a medical specialty), and in our country, at first place, followed by pediatricians ${ }^{26,27}$.

The emotional fatigue reported by dermatologists is similar to that of physicians from other specialties. This may be due to the fact that in the doctor-patient relationship there will be always emotional demands, regardless of or beyond the area of practice, due to the influence of health institutions' organizational factors, such as material resources being insufficient or decision-making not being shared, among other. Although subjective-nature problems have different origins, dermatologists, for example, have to treat patients with chronic diseases that seriously affect the quality of life, whereas other specialists have to confront mutilation or lethal cases more often ${ }^{28}$.

The experiences obtained during the training of students in medical school are important to determine their choice of one or another specialty ${ }^{29-31}$. These 
include exposure to a particular working area, interaction with a positive leader or research activities on a specific subject. In addition, there are other factors that are modifiable or not, such as age, gender, marital status and grades on exams. Modifiable factors include liking intellectual challenges, future opportunities to work in private practice, training time, competition conditions, long-term relationship with patients, lifestyle, whether the specialty implies respect, presence of emergencies or not, medical and social prestige, a role model to follow, economic reward, gender distribution in the specialty, technological challenge, diversity of cases and patients, personal experience with diseases of a particular area, and the selection of schoolmates at medical training ${ }^{32}$.

Particular factors that influence for a physician to select dermatology as specialty include the time he/ she coexists with this area during his/her training and experience on the field before and after graduating, or else with other related fields such as rheumatology or internal medicine; furthermore, one of the determining factors appears to be the relationship experienced by the student with a skin specialist, which inspires $\mathrm{him} /$ her to choose this path. Some other relevant considerations are low competition, few emergency requests and the possibility of having schedules that are compatible with family life ${ }^{32,33}$.

International literature has reported that, for different reasons, dermatologists have more job satisfaction and less stress than physicians in other areas ${ }^{34}$. Therefore, it is possible that skin specialist physicians have specific needs and emotional perceptions, which establish some of their emotional, affective and psychological well-being conditions and, in consequence, their job satisfaction.

In the year 2007, Clayton et al. ${ }^{33}$ conducted a study in the United Kingdom with an electronic questionnaire directed to members of the British Society of Dermatology, and concluded that $93 \%$ of surveyed subjects were happy to have chosen dermatology as specialty and that they expected to continue practicing it until retirement. In our research we had concordant data, since we found that the degree of satisfaction with the specialty was $93.2 \%$.

Residents contribute to medical education by offering valuable during feedback exercises, as well as in assessments of the curriculums of the places where they receive their specialty training.

In 2008, Freeman et al..$^{35}$ reported a study about a group of dermatology residents in the USA, where the degree of satisfaction with regard to their training and medical tutorial support was evaluated. They agreed that tutorial support is a positive influence, and also relevant to the direction their career and scientific productivity take in the area of research. Increased satisfaction with their residency was associated with study programs' specific characteristics, where there were high-quality tutors with time available to interact with them. Thy concluded that maintaining residents' interest on clinical and academic practice with enriching practices by their tutors is a constant concern, and suggested measures to increase the number of aspirants seeking an academic career. Another factor that was considered to be relevant was their training in the following areas: clinical, dermatopathology, cosmetic dermatology, pediatric dermatology and business management. It should be pointed out that the latter three are rather uncommon in most training programs, and that they were found to generate a lower degree of satisfaction.

In our findings, we didn't find any relationship between the degree of satisfaction with the specialty and the institution of medical training, since the majority was found to be "very satisfied" $(75.3 \%)$ or "moderately satisfied" (21.5\%) with their academic training. We consider that this reveals an area of opportunity to improve internal programs at each training hospital and this way foster adherence to the alma mater. Most participants in the survey were graduates from medical institutions of Mexico City (64.8\%).

Currently, knowledge on well-being in people's life is relevant; its measurement is not only a way to assess feelings and psychological abilities of the human being, but also a central aspect of models to understand psycho-emotional health. Assessment of this phenomenon is crucial to validate theories and models of happiness, as well as to measure the results of possible favorable interventions, particularly those of a clinical nature ${ }^{36}$.

Different mechanisms have been proposed to assess population happiness and its predictors. These include, for example, per capita income, health status, social support, freedom of choice, generosity, the perception of corruption, positive or negative affections, expectations and more $^{37}$.

A scale is a construct designed to measure the true status of a quality of interest, and it is also an ordered succession of distinct values belonging to a same quality. A scale is a series of values or grades that can be placed within the same contingency or quantitative situation $^{38}$. Some scales cover components or aspects related to well-being (satisfaction with life, positive 
emotions, psychological functioning, social status), but have the disadvantage of covering a single dimension. The process of emotional analysis is complex, since psychological well-being can be assessed with different markers or with regard to time (retrospective or immediate), a fact that increases the difficulty to develop a deep and comprehensive measurement ${ }^{8}$.

PHI was validated in 2013 by Hervás and Vázquez ${ }^{8}$ by means of an analysis of 4052 subjects of between 16 and 60 years of age. It identifies well-being factors in order to this way provide a reference that encompasses the most relevant domains indicated in the literature and at different time margins. It includes both well-being that is experienced at the moment of its execution and that which is remembered; in addition, it identifies the sum of positive experiences and the absence of negative experiences in the previous day. This tool is validated in 7 languages (including Spanish) and in 9 countries (including Mexico), which increases its transcultural value. This is why we decided to use this element of analysis for the development of this investigation. Our results reveal that $\mathrm{PHI}$ is reliable, with a well-defined dimensionality, and that it is also consistent with other subsets of samples of the same population.

In this scale we obtained a mean score of 9.08 , which is interpreted as being high and that can be defined as a state of "deep well-being" and of "commitment and satisfaction with life"; hence, based on these answers, the degree of happiness is high. This is consistent with findings described in the international literature, which place dermatology within the highest places of satisfaction in comparison with other specialties.

Knowledge of these references and of the conditions detected in other latitudes enables us to establish follow-up markers and comparative dimensions in the emotional and affective areas in our setting.

According to reports in the United States literature, dermatology is one of the specialties that generates higher satisfaction among physicians, and probably this is owing to: 1) opportunities of a prosperous job; 2) the possibility to preserve, by personal reference, a constant flow of patients with skin problems; 3 ) more acceptable working hours than other specialties, and 4) treatment results are usually direct, on the short- or mid-term, and evident for patients, which favors a good doctor-patient relationship ${ }^{33,39}$.

In our research, the most relevant reasons for satisfaction were elements related to medical-surgical practical exercise, being able to help and the scientific area. In addition, we consider that there are other elements that might secondarily or complementarily influence on the revealed satisfaction, such as the obtained social status, the possibility of establishing friendship bonds, economic remuneration, not having to frequently face lethal cases, not having so demanding or frequent night shifts as in other specialties, frequent travels to medical congresses and having reasonable working hours and, consequently, time available to carry out activities other than work, among others.

The study by Arias-Santiago et al..$^{40}$, conducted in Granada, Spain in 2011, reported that quality of life in a group of local dermatologists was moderate since although they had a strong intrinsic motivation, the support they received from their superiors was from low to moderate, and they had a large amount of work and a high grade of responsibility. We interpret that these results differ from ours because health system in Spain is different from the Mexican; however, it would be interesting to later assess satisfaction differences between doctors who practice in an institution and those who exercise only private medicine or those who practice both in one country and the other.

The most current and thorough study on satisfaction status with doctors' compensations was carried out by Peckham ${ }^{41}$ in 2016, with a survey applied to more than 19,000 physicians from 26 specialties in the USA. For them, the main aspects of job rewards were gratitude and relationship with patients. Relevant data for dermatologists revealed that they are the third ones with the highest economic yearly perceptions, after orthopedists and cardiologists; and they are number one on feeling fairly gratified, satisfied with their career and specialty and, in consequence, with their profession comprehensively. It drew our attention that only $74 \%$ of surveyed subjects would choose this specialty again, whereas in our report, figures close to $99 \%$ were reached.

When dimensionality factors were assessed, the highest values were found in items "I think my professional life is useful and worthwhile" and "I think I can be myself on the important things", which are situations that can translate into that the fact of feeling useful in our profession and the sensation of autonomy are relevant factors.

Although for the moment there are no local studies on this subject, we question ourselves if particular influences of our setting and surroundings, such as ethnic, social, cultural, economic, participation in the community, public hierarchy, acquisitive and other 
factors can be, they might be stimuli for happiness perception in the medical generality. The largest and more recent studies on happiness in the entire world, place Mexico at the $21^{\text {st }}$ position of the global ranking and at fourth place in Latin America, after Costa Rica, Puerto Rico and Brazil ${ }^{37}$.

Other elements might be the time distributed between institutional and private practice, or the hours specifically dedicated to the workday, and the economic retribution with this regard. In Mexico, the level of monetary perception in different specialties has not been identified, whereas in the USA, as previously mentioned, dermatologists are at third place in that area ${ }^{41}$.

We estimate that the data obtained in this type of investigations, among other things, will reveal the possibility of implementing tools to confront phenomena in medical practice such as professional burnout syndrome (in the International Classification of Diseases. ICD-z73.0), where there are high degrees of emotional exhaustion, depersonalization and low selffulfillment ${ }^{42,43}$.

A report on USA physicians' lifestyle ${ }^{44}$ indicated that dermatologists experience low levels of professional burnout syndrome in comparison with other specialists, and that they are number one in happiness status, both on and off work; in addition they are the physicians that practice more exercise per week and the ones with the lowest overweight indices.

An interesting finding is gender distribution, since more than $70 \%$ of participants in our study were women, and in other places dermatology has also been reported to be one of the specialties where females are predominant after obstetrics \& gynecology, pediatrics, pathology and psychiatry ${ }^{41}$. Is it then that female particular perceptions of happiness influence on statistics? We believe it is so.

We understand that the singular characteristics of the environment where dermatologists develop themselves in Mexico are favorable, not only in the professional field, but also are accompanied by elements of social, economic, familiar, climatological and interpersonal coexistence well-being, which in our cultural sphere stand out as of great appreciation and value for life itself.

\section{Conclusions}

We can say that dermatologists in Mexico have high indices of satisfaction and happiness as regards their life and profession.
At the moment of this study, there were 16 teaching hospitals dedicated to the academic training of dermatology specialists, and most participants were found to be highly satisfied with their postgraduate training institution.

The most relevant reasons to speak positively of the specialty were related to the spheres of medical and humanistic exercise. We perceive that dermatology enables having professional satisfactions in different fields, which is consistent with the possibility for fulfillment in personal and familiar life to be achieved by the specialist, and hence almost the totality of surveyed subjects would choose this branch of medicine again.

Among dermatologists, the fact of feeling useful, valuable and with the capability of maintaining autonomy is highly important.

$\mathrm{PHI}$ worked very well as an assessment scale in our investigation.

To the best of our knowledge, this is the first study on the subject in our setting, and in addition to being able to awaken interest in the academic sphere, we consider it will serve as a precedent for new investigations.

The present work had the approval and the corresponding registries at the Directorate of Research (DI/15/109/03/086), the Research Committee (Cl/88/15) and the Ethics Committee (CE/737/15) of Hospital General de México Dr. Eduardo Liceaga, which belongs to the Ministry of Health.

\section{Acknowledgements}

We thank the Mexican Society of Dermatology and the Mexican Academy of Dermatologic and Oncologic Surgery for their support in the diffusion of the survey instrument. We also thank Dr. Julieta Fierro-Gossman for conceptual counselling regarding this project.

\section{References}

1. McMahon DM. Happiness: a history. New York: Grove Press; 2006. p. 353-453.

2. Organización Mundial de la Salud. Salud mental: un estado de bienestar. Diciembre 2013. (Consultado en junio de 2016.) Disponible en: www. who.int/features/factfiles/mental health/es

3. Vázquez C, Hervás G, Rahona JJ, et al. Bienestar psicológico y salud: aportaciones desde la psicología positiva. Ann Clin Health-Psychol. 2009;5:15-28.

4. Ryff CD. Psychological well-being in adult life. Curr Dir Psychol Sci. 1995;4:99-104.

5. Vázquez C, Duque A, Hervás G. Satisfaction with life scale in a representative sample of Spanish adults: validation and normative data. Span J Psychol. 2013;16:1-15.

6. Warr P. Sources of happiness and unhappiness in the workplace: a combined perspective. J Work Organizational Psychol. 2013;29:99-106.

7. Daniel WW. Bioestadística: base para el análisis de las ciencias de la salud. $4^{a}$ ed. México: Limusa Wiley; 2001. p. 138. 
8. Hervás $G$, Vázquez $C$. Construction and validation of a measure of integrative well-being in seven languages: the Pemberton Happiness Index. Health Qual Life Outcomes. 2013;11:66.

9. Hair JF Jr, Black WC, Babin BJ, Anderson RE. Multivariate data analisis. $7^{\text {th }}$ ed. New Jersey: Prentice Hall; 2010. p. 91-138, 469-518.

10. Netemeyer RG, Bearden WO, Sharma S. Scaling procedures: issues and applications. California: Sage; 2003. p. 8-15.

11. Real Academia Española. Diccionario de la Lengua Española. (Consultado en junio de 2016.) Disponible en: http://dle.rae.es/?id=Hj4JtKk

12. Academia Mexicana de la Lengua. (Consultado en junio de 2016.) Disponible en: http://www.academia.org.mx/felicidad

13. Rayo L, Becker GS. Evolutionary efficiency and happiness. Journal of Political Economy. 2007;115:302-37.

14. Williams ES, Konrad TR, Linzer M, et al. Refining the measurement of physician job satisfaction: results from the Physician Worklife Survey. SGIM Career Satisfaction Study Group. Society of General Internal Medicine. Med Care. 1999;37:1140-54.

15. Konrad TR, Williams ES, Linzer M. Measuring physician job satisfaction in a changing workplace and a challenging environment. SGIM Career Satisfaction Study Group. Society of General Internal Medicine. Med Care. 1999;37:1174-82

16. Aiken LH, Clarke SP, Sloane DM, et al. Hospital nurse staffing and patient mortality, nurse burnout, and job dissatisfaction. JAMA. 2002 288:1987-93.

17. Ramírez AJ, Graham J, Richards MA, et al. Mental health of hospital consultants: the effects of stress and satisfaction at work. Lancet. 1996;347:724-8.

18. Bascuñán ML. Cambios en la relación médico-paciente y nivel de satisfacción de los médicos. Rev Med Chile. 2005:133:11-6.

19. De la Rosa-Rojas G, Chang-Grozo S, Delgado-Flores L, et al. Niveles de estrés y formas de afrontamiento en estudiantes de Medicina en comparación con estudiantes de otras escuelas. Gac Med Mex. 2015; 151:443-9.

20. Mingote-Adán JC, Moreno-Jiménez B, Gálvez-Herrer M. Burnout and the health of the medical professionals: review and preventive offers. Med Clin (Barc). 2004;123:265-70.

21. Paris L, Omar A. Predictors of job satisfaction among physicians and nurses. Estudios de Psicología. 2008;13:233-44.

22. Kassirer J. Doctor discontent. N Engl J Med. 1998;339:1543-5.

23. Smith $\mathrm{R}$. Why are doctors so unhappy? There are probably many causes, some of them deep. BMJ. 2001;322:1073-4.

24. Zuger A. Dissatisfaction with medical practice. N Eng J Med. 2004;350: 69-75.

25. Nylenna M, Glubrandsen P, Førde R, et al. Job satisfaction among Norwegian general practitioners. Scand J Prim Health Care. 2005 23:198-202.

26. IM Médico. El ranking de médicos más felices de España según su especialidad. (Consultado en junio de 2016.) Disponible en: http://www. immedicohospitalario.es/noticia/7217/el-ranking-de-medicos-mas-felicesde-espana-segun-su-especialidad

27. Notimex. ¿Quiénes son los profesionales más felices? Disponible en: http://www.zocalo.com.mx/seccion/articulo/quienes-son-los-profesionales-mas-felices-1458309442

28. Renzi C, Tabolli S, lanni A, et al. Burnout and job satisfaction comparing healthcare staff of a dermatological hospital and a general hospital. J Eur Acad Dermatol Venereol. 2005;19:154-7.

29. Schwartz RW, Jarecky RK, Strodel WE, et al. Controllable lifestyle: a new factor in career choice by medical students. Acad Med. 1989;64:606-9.

30. Erzurum VZ, Obermeyer RJ, Fecher A, et al. What influences medical students' choice of surgical careers. Surgery. 2000;128:253-6.

31. Chen H, Hardacre JM, Martin C, et al. Do medical school surgical rotations influence subspecialty choice? J Surg Res. 2001;97:172-8.

32. Ibrahim M, Fanshawe A, Patel V, et al. What factors influence British medical students' career intentions? Med Teach. 2014;36:1067-72.

33. Clayton R, Lambert T, Burge SM. Career choices in dermatology. Clin Exp Dermatol. 2010;35:86-90.

34. Leigh JP, Tancredi DJ, Kravitz RL. Physician career satisfaction within specialties. BMC Health Serv Res. 2009;9:166.

35. Freeman SR, Greene RE, Kimball AB, et al. US dematology residents' satisfaction with training and mentoring: survey results from the 2005 and 2006 Las Vegas Dermatology Seminars. Arch Dermatol. 2008;144: 896-900.

36. Diener E. Subjective well-being. The science of happiness and a proposal for a national index. Am Psychol. 2000;55:34-43.

37. Helliwell J, Layard R, Sachs J. World Happiness Report 2016, Update (Vol. I). New York: Sustainable Development Solutions Network. 2016. (Consultado en junio de 2016.) Disponible en: http://worldhappiness.report/wp-content/uploads/sites/2/2016/03/HR-V1_web.pdf

38. DefiniciónABC. Escala. (Consultado en junio de 2016.) Disponible en: http://www.definicionabc.com/ciencia/escala.php

39. Kimball AB. Dermatology: a unique case of specialty work-force economics. J Am Acad Dermatol. 2003;48:265-70.

40. Arias-Santiago S, Buendía-Elsman A, Husein-ElAhmed $\mathrm{H}$, et al. Perception of dermatologist quality of life. J Am Acad Dermatol. 2011;64: S1-AB80.

41. Peckham C. Medscape physician compensation report. Medscape apr. 1, 2016. (Consultado en junio de 2016.) Disponible en: http://www.medscape.com/features/slideshow/compensation/2016/public/overview

42. Hidalgo-Vicario MI. Burnout syndrome. Ped Int. 2016;20:5-6.

43. Catálogo de Enfermedades eCIE10ES, Gobierno de España. Ministerio de Sanidad, Servicios Sociales e Igualdad. Disponible en: http://eciemaps.msssi.gob.es/ecieMaps/browser/indexMapping.htmI\#code $=Z 73.0 \&$ source $=$ cie $10 \mathrm{mc} \&$ target $=$ cie $9 \mathrm{mc}$

44. Peckerham C. Medscape lifestyle report 2016: bias and burnout Medscape Jan 13, 2016. Disponible en: https://www.medscape.com/slideshow/lifestyle-2016-overview-6007335\#page $=1$ 